\title{
Implementation of High Speed Long Reach Hybrid Radio over Multimode Transmission System
}

\author{
Pardeep kaur \\ M.Tech \\ Department of Electronics and \\ communication, \\ Punjabi University, Patiala
}

\author{
Rajbir kaur \\ Assistant Professor \\ Department of Electronics and \\ communication, \\ Punjabi University, Patiala
}

\author{
Sushank chaudhary \\ PhD Scholar \\ Optical technology Group \\ InterNetworks Research \\ Lab,UUM Malaysia.
}

\begin{abstract}
Radio over fiber (RoF) is one of the primary technologies for the provision of future broadband networks. This work is focused to the implementation of cost effective radio over multimode system (Ro-MMF) for long haul communication. A $10 \mathrm{Gbps}$ data along with $10 \mathrm{GHz}$ radio signal is transmitted over multimode fiber link of $40 \mathrm{~km}$. Moreover, the results are also reported for proposed Ro-MMF system by using LG 00 , LG 01 \& LG 02 modes.
\end{abstract}

\section{Keywords}

Radio over multimode system (Ro-MMF), LG modes, Radio over Fiber (RoF)

\section{INTRODUCTION}

From the last decade, there has been huge increase in the deployment of broadband networks all around the world. The demand of more bandwidth due to rapid growth of subscribers day by day has been led to the development of new optical technologies and devices. To fulfill this needs of subscribers, mobile communication requires large number of base stations to handle more users, which leads to increase in the cost of deployment. One such solution to this problem is Radio over Fiber (RoF) technology. RoF refer to a technology, which allows the radio signal transported over optical fiber to assist wireless access. It is an integration of wireless and optical system, which proves as seductive solution for increasing capacity as well as decreasing costs in areas such as airports, hotels and offices etc. [1-2]. It entails the sharing of all functions such as RF up-conversion/ down-conversion, signaling, amplification etc. from the central station to the base stations which results in reduction of the cost at the base stations. By allowing the combination of optical networks with the mobility of wireless networks due to reduction of complexity at antenna sites, it becomes promising solutions for the cellular networks [3]. From the last decade, multimode fibers (MMF) are widely use in-building scenarios, which allow less severe alignment lenience because of its large core diameter. MMF can also easily installed in buildings with high penetration [4-5]. Low cost and high speeds are the other advantages of MMF. The use of MMF can be a lucrative solution for RoF system. The distances are fairly short for indoor applications; hence choosing MMFs is the judicious choice [6]. Various investigations have been performed to improve the low-cost Radio-over-multimode fiber system (Ro-MMF) with short multimode fiber by using receiver improvement scheme, model dispersion compensation scheme [6] and mode filter scheme [7]. In small-scale buildings, the
Ro-MMF systems can be used distributed antennas to provide proper coverage. Nevertheless, the signal hauling capacity in Ro-MMF system can be indigent than Radio over single mode fiber (Ro-SMF) [6-8]. To renovate such systems, some researchers take attention towards some novel techniques such as evaluate the Ro-MMF system by using low cost $850 \mathrm{~nm}$ vertical cavity surface emitting laser (VCSEL) and 50$\mu \mathrm{m} / 62.5$ - $\mu$ mcore matched photodiodes [9]. In addition to this, another researcher explored the contingency of using RoMMF system to broadcast Ultra wide band (UWB) radio transmitted through MMF link with fiber length $(200 \mathrm{~m}, 300 \mathrm{~m}$ and $600 \mathrm{~m}$ ) by using VCSEL laser [10]. Furthermore, some researchers worked on this area based on cost reduction of RoF systems by employing some RoF extension schemes such as UWB based localization and positioning as well as wide coverage area using Pico-cells concept for communication network. These approaches examine the contribution of intermodal distortion that may be produced in MMF links [11]. Constantly emerging cloud-computing technology requires high-speed optical links with high data rates [12]. Spatial Laser employed LG modes operating in 850/1550 nm and Multimode fibers (MMFs) have been an optimal consolidation for short haul transmission. Laguerre-Gaussian (LG) modes generated using spatial laser have rotational symmetry along their propagation axis modes in which the field components in the direction of propagation are small compared to components perpendicular to that direction [13]. In this work, we have designed a high speed Ro-MMF system for the transmission of $10 \mathrm{Gbps}$ data along with radio signal of $10 \mathrm{GHz}$ over optical span of $40 \mathrm{~km}$. Furthermore; the roles of LG modes $(00,01 \& 02)$ are also investigated in the proposed Ro-MMF system. The rest of the paper is divided into following sections: Section 2 describes the Simulation setup, results from the simulation set up are presented and discussed in section 3 followed by the section 4 which describes the conclusion.

\section{SYSTEM DESCRIPTION:}

The simulation setup for proposed $10 \mathrm{Gbps}-10 \mathrm{GHz}-\mathrm{Ro}-$ MMF is shown in Fig.1. A 10 Gbps data generated by pseudorandom bit generator is fed to non-return to zero (NRZ) encoder and then mixed with $10 \mathrm{GHz}$ radio signal. This $10 \mathrm{GHz}-10 \mathrm{Gbps}$ signal is optically modulated by using $\mathrm{LiNb}_{3}$ modulator derived by spatial continuous wave (CW) laser. Using same spatial laser as shown in the Fig 2 generates LG 00, LG $01 \&$ LG 02. The optical signal from optical modulator is transmitted over multimode fiber having span of $40 \mathrm{~km}$. At the reception side, spatial avalanche photo diode (APD) is used for receiving the optical signal. The output of 
APD is then fed to low pass cosine filter having 0.5 roll off factor to recover $10 \mathrm{GHz}$ radio signal and $10 \mathrm{Gbps}$ data.

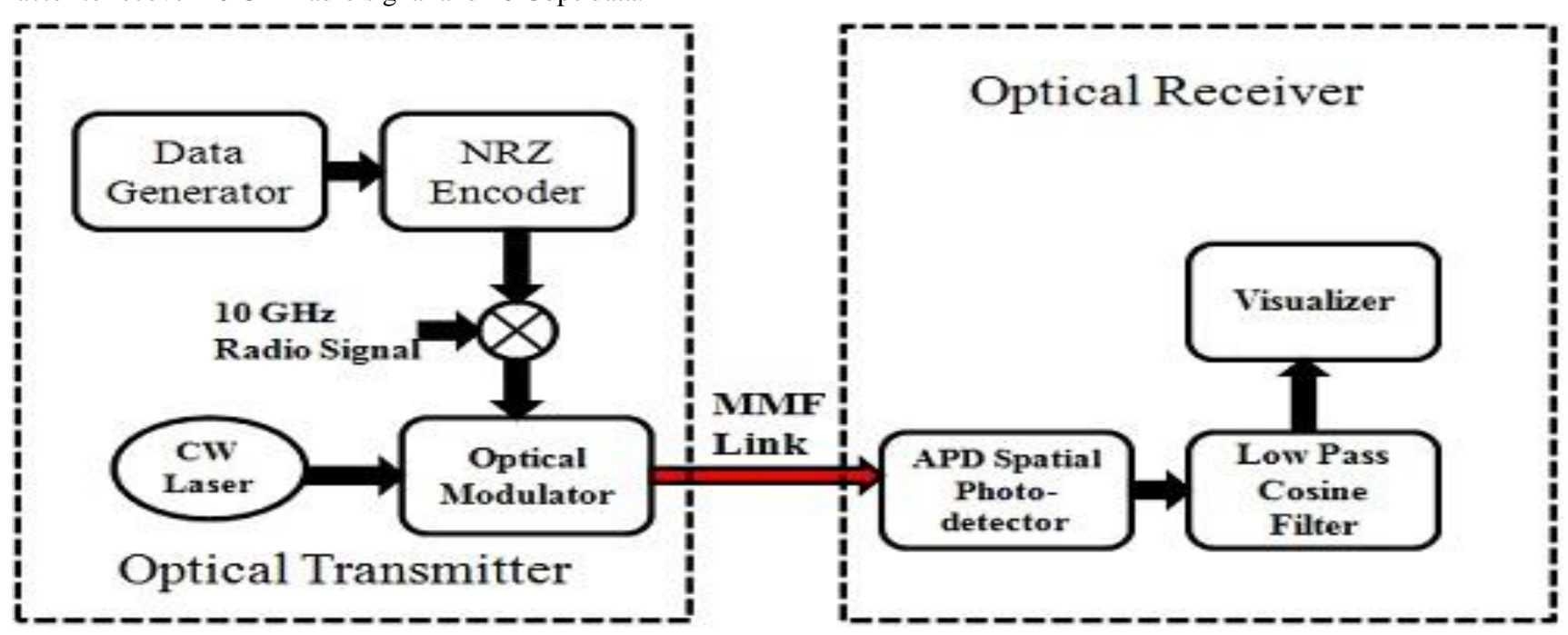

Fig.1 Architecture of proposed system

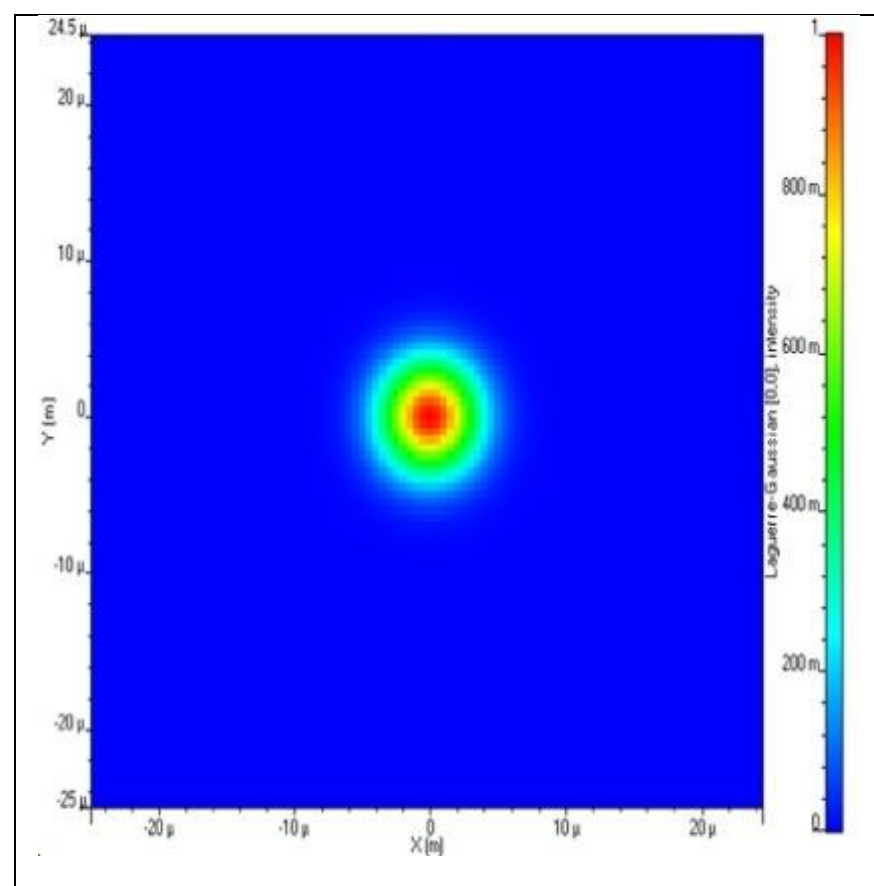

(a)

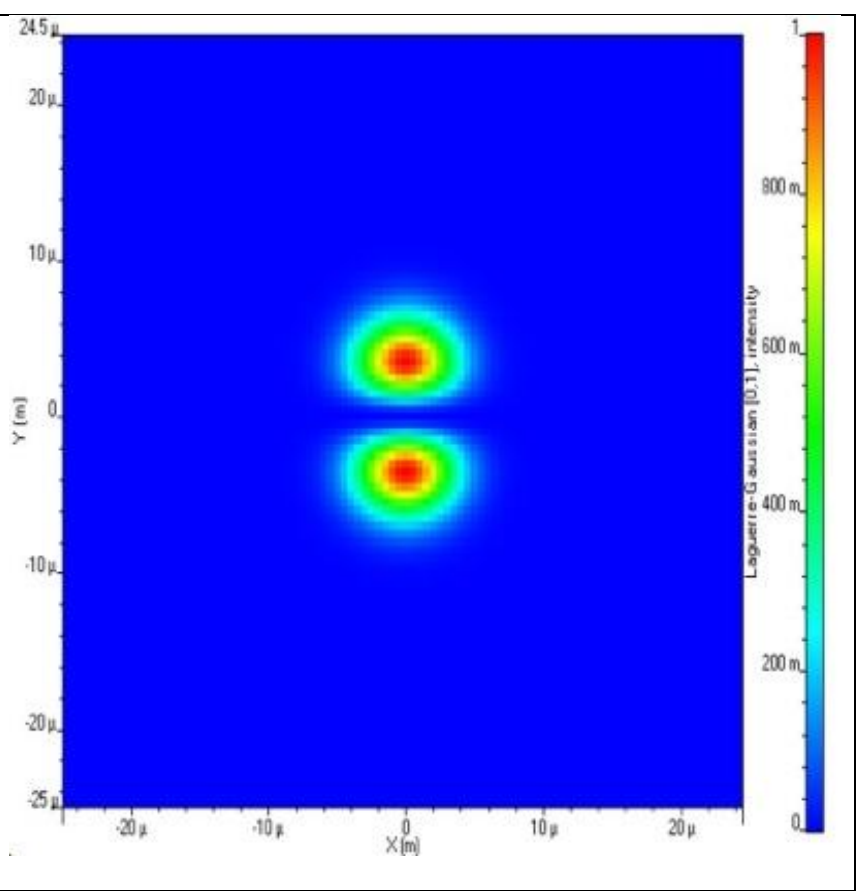

(b) 


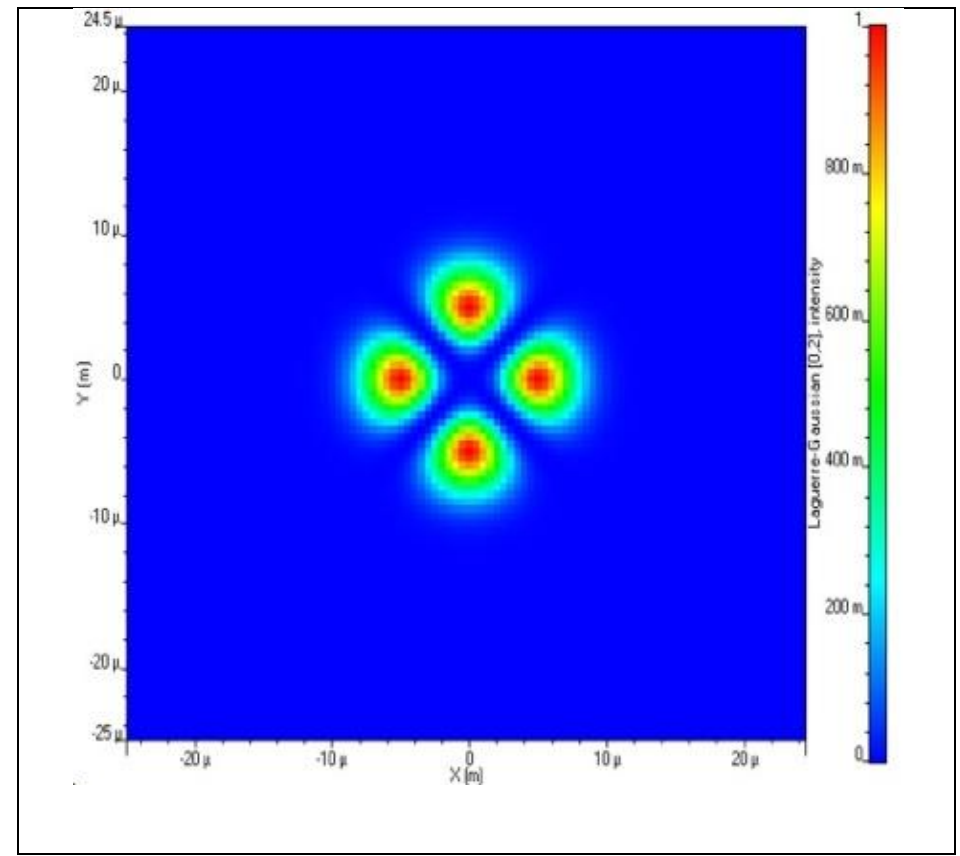

(c)

Fig.2 LG modes excited by Spatial Laser (a) LG 00 mode (b) LG 01 mode (c) LG 02 mode

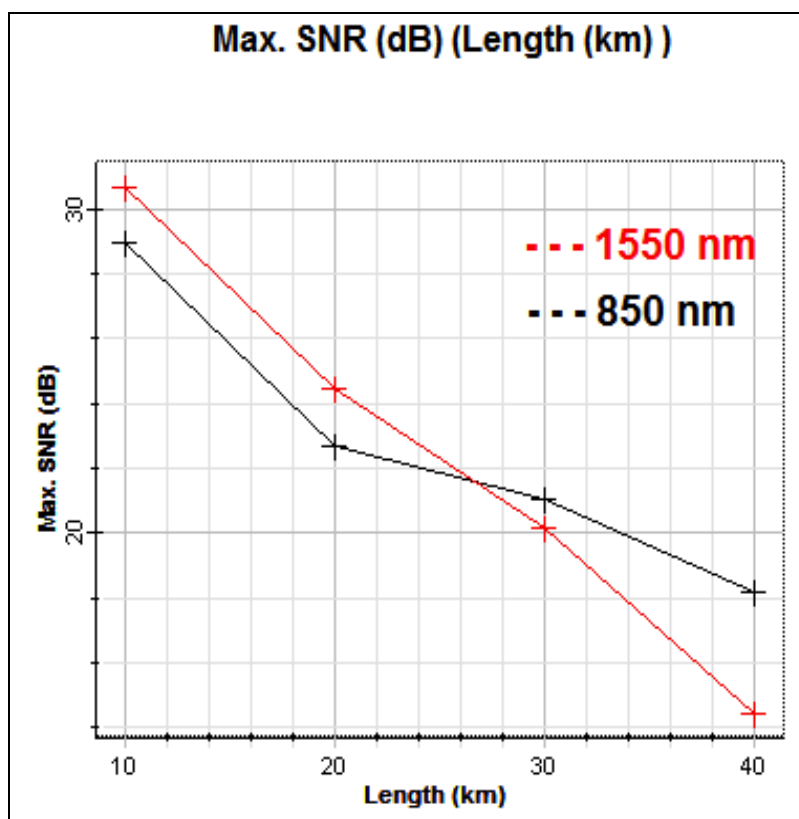

(a)

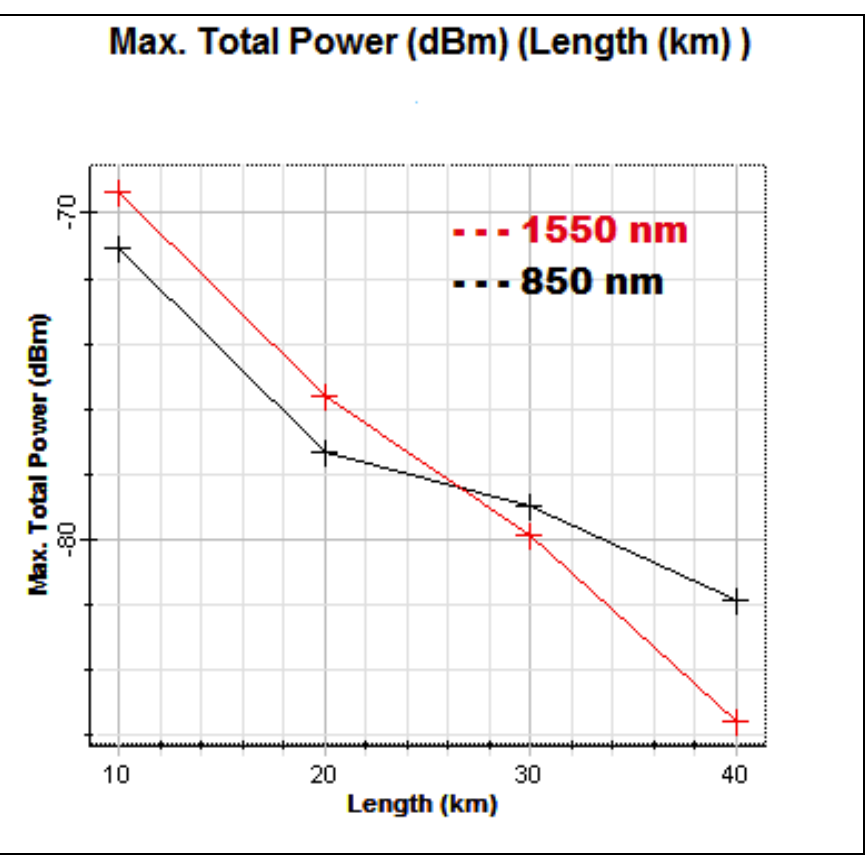

(b)

Fig 3: Comparison of operating wavelengths (a) SNR (b) Total Received Power

\section{RESULTS AND DISCUSSIONS:}

In this section, the results obtained from proposed $10 \mathrm{GHz}-10$ Gbps hybrid RoF system are presented and discussed. The performance of our proposed system is investigated in terms of SNR, Eye diagrams and Total received power. Fig 3 shows the transmission of signal over optical span by using operating wavelength of $850 \mathrm{~nm}$ and $1550 \mathrm{~nm}$ in terms of SNR and total received power. It has been shown from fig. 3(a) that an improvement of $2 \mathrm{~dB}$ in SNR is noticed when transmitted using $1550 \mathrm{~nm}$ as compared to $850 \mathrm{~nm}$ at the distance of 10 $\mathrm{km}$ but when the transmission distance is increased then an improvement of $4.24 \mathrm{~dB}$ is computed in case of $850 \mathrm{~nm}$ as compared to $1550 \mathrm{~nm}$ at the distance of $40 \mathrm{~km}$ of multimode 
fiber. Similarly, an improvement of $-5 \mathrm{~dB}$ is noticed from fig 3 (b) in case of $850 \mathrm{~nm}$ as compared to $1550 \mathrm{~nm}$ at the multimode fiber link of $40 \mathrm{~km}$

Fig 4 reveals the investigation of various LG modes for proposed Ro-MMF transmission system. It has been shown from the fig 4 (a) that the value of SNR for LG 00 mode is computed as $28.65 \mathrm{~dB}, 21.56 \mathrm{~dB} \& 17.50 \mathrm{~dB}$; for LG 01 mode it is computed as $25.79 \mathrm{~dB}, 18.15 \mathrm{~dB} \& 15.37 \mathrm{~dB}$; for LG 02 mode it is computed as $20.95 \mathrm{~dB}, 12.26 \mathrm{~dB} \& 8.37 \mathrm{~dB}$ at the distance of $10 \mathrm{~km}, 30 \mathrm{~km} \& 40 \mathrm{~km}$ respectively. Similarly, the value of total power for LG 00 mode is computed as -71.34 $\mathrm{dBm},-74.48 \mathrm{dBm} \&-82.49 \mathrm{dBm}$; for LG 01 mode it is -74.20 $\mathrm{dBm},-81.83 \mathrm{dBm} \&-84.60 \mathrm{dBm}$; for LG 02 mode it is $79.04 \mathrm{dBm},-87.73 \mathrm{dBm} \&-91.59 \mathrm{dBm}$ at the multimode fiber link of $10 \mathrm{~km}, 30 \mathrm{~km} \& 40 \mathrm{~km}$ respectively. Moreover, it is cleared from the table 1 that LG 00 mode has better performance as compared to the LG 01 and LG 02 modes in terms of SNR and total received power. By using LG 00 mode, the multimode transmission link will prolong to $30 \mathrm{~km}$ where as for LG 01 mode and LG 02 mode, the multimode link will prolong to $20 \mathrm{~km}$ and $10 \mathrm{~km}$ respectively with acceptable SNR and total received power.

The Fig 5 shows the eye diagrams for LG 00, LG 01 \& LG 02 modes at the fiber link of $40 \mathrm{~km}$. It has been reported that the eye diagram for LG 00 mode is more precised as compared to the LG 01 and LG 02 modes. As the modes are changing from LG 00 towards LG 02 mode, the eye is getting distorted in terms of noise.

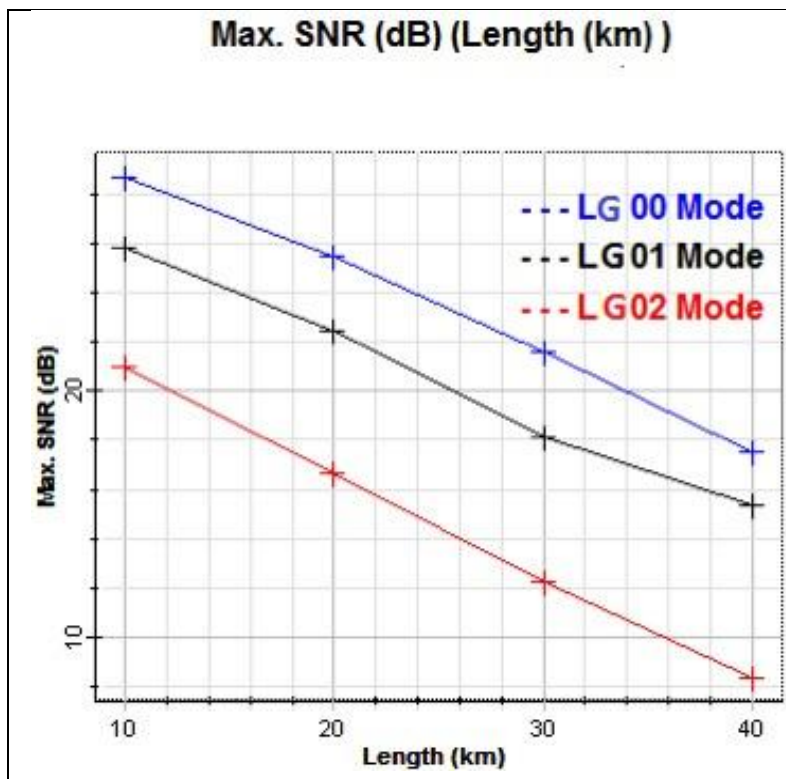

(a)

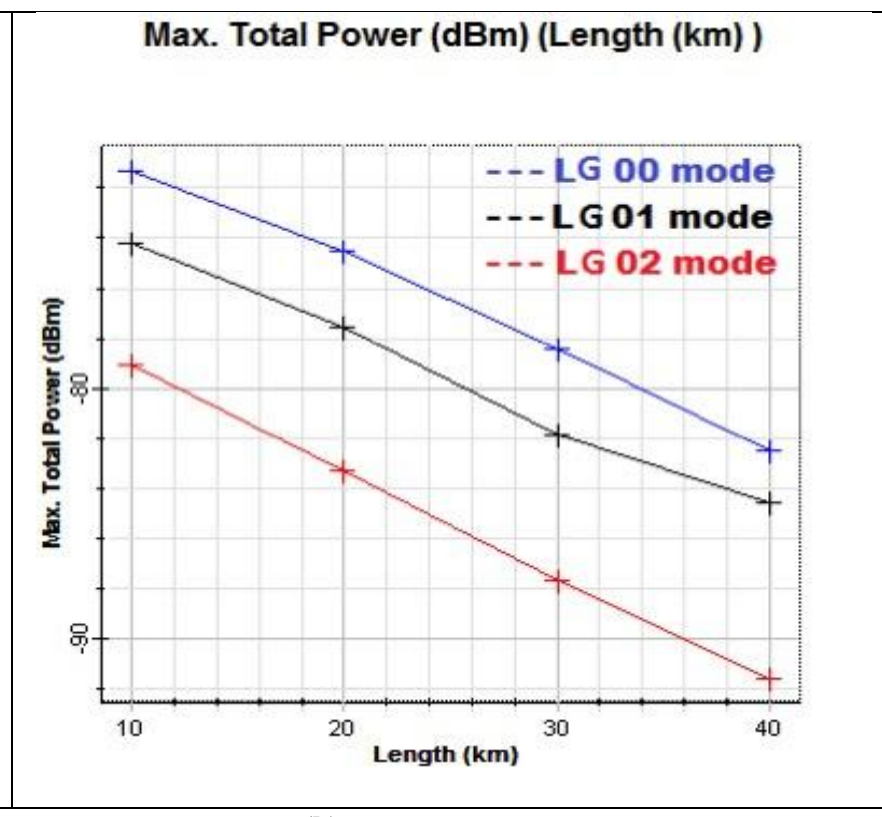

(b)

Fig 4 Investigation of LG Modes (a) SNR (b) Total Received Power

\begin{tabular}{|c|c|c|c|c|c|c|}
\hline \multirow{2}{*}{$\begin{array}{c}\text { Fiber Length } \\
(\mathrm{Km})\end{array}$} & \multicolumn{2}{|c|}{ LG 00 mode } & \multicolumn{2}{c|}{ LG 01 mode } & \multicolumn{2}{c|}{ LG 02 mode } \\
\cline { 2 - 7 } & SNR (dB) & $\begin{array}{c}\text { Total power } \\
(\mathrm{dBm})\end{array}$ & SNR $(\mathrm{dB})$ & $\begin{array}{c}\text { Total Power } \\
(\mathrm{dBm})\end{array}$ & $\begin{array}{c}\text { SNR }(\mathrm{dB}) \\
(\mathrm{dBm})\end{array}$ \\
\hline 10 & 28.65 & -71.34 & 25.79 & -74.20 & 20.95 & -79.04 \\
\hline 20 & 25.51 & -74.48 & 22.47 & -77.51 & 16.65 & -83.33 \\
\hline 30 & 21.56 & -78.43 & 18.15 & -81.83 & 12.26 & -87.73 \\
\hline 40 & 17.50 & -82.49 & 15.37 & -84.60 & 8.37 & -91.59 \\
\hline
\end{tabular}

Table 1: Evaluation of SNR and Total Received power against fiber link for LG modes 


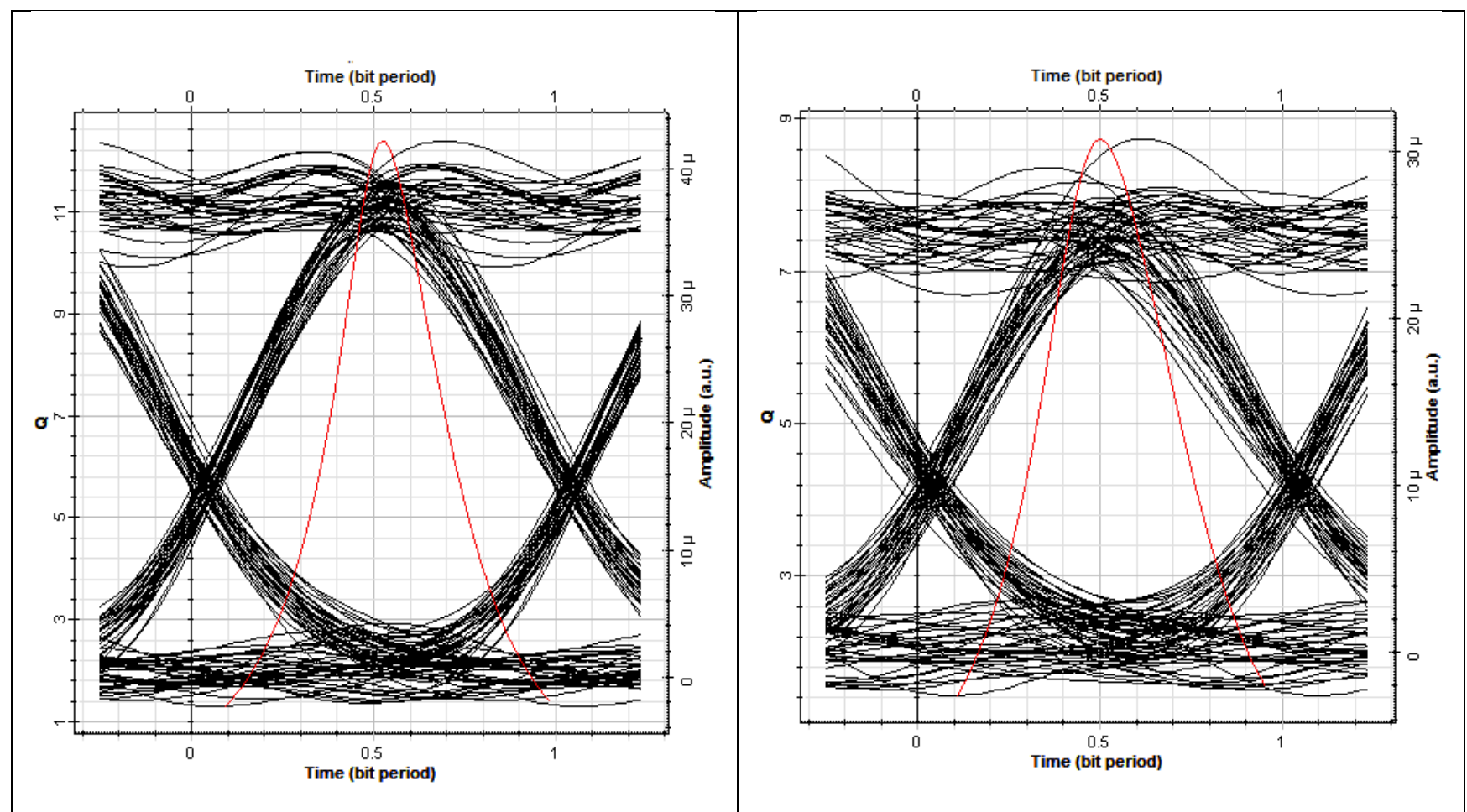

(a)

(b)

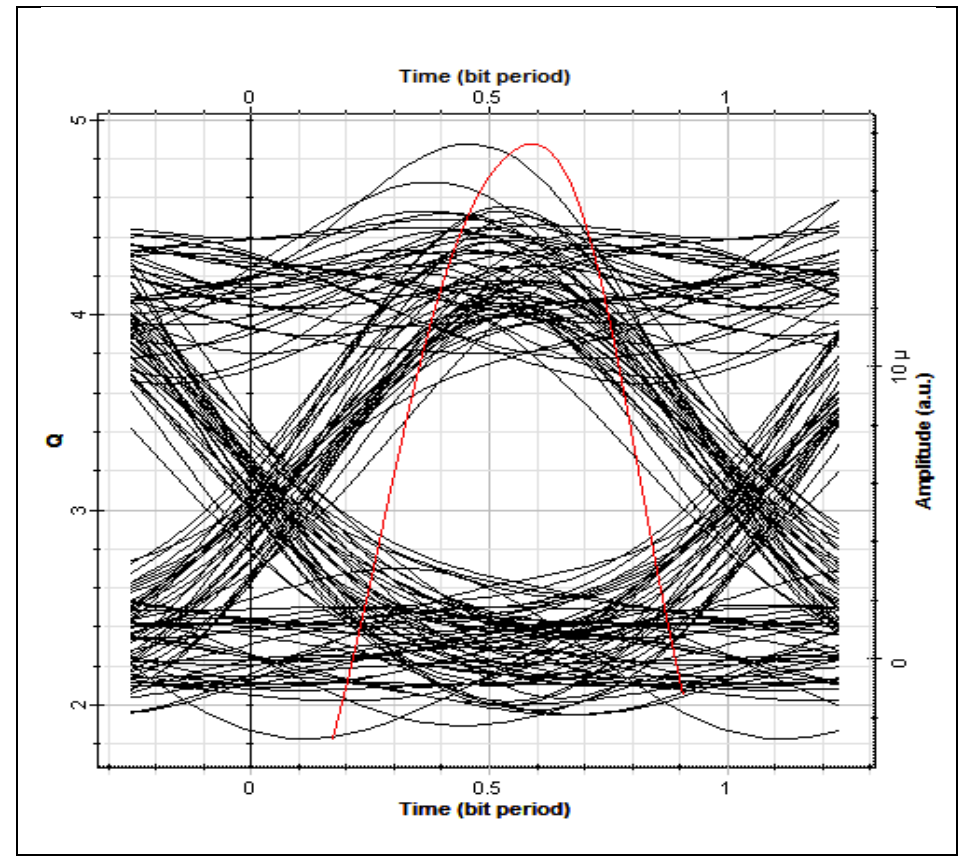

(c)

Fig 5: Eye Diagrams at multimode link of $40 \mathrm{~km}$ (a) LG 00 mode (b) LG 01 mode (c) LG 02 mode.

\section{CONCLUSION:}

In this work, we have presented a novel technique for shortrange, cost-effective Ro-MMF system for transmission of 10 $\mathrm{GHz}$ radio signal along with $10 \mathrm{Gbps}$ data. Furthermore, the performance of proposed system using LG 00 mode, LG 01 mode \& LG 02 mode through the MMF link has been evaluated. It is concluded that LG 00 mode is considered to best as compared to LG 01 and LG 02 modes for the proposed
$10 \mathrm{GHz}-10 \mathrm{Gbps}$ Ro-MMF system. By using LG 00 mode, the MMF link can be extended to $30 \mathrm{~km}$ as compared to the LG $01 \&$ LG 02 modes for which the MMF link will prolongs to $20 \mathrm{~km}$ and $10 \mathrm{~km}$ respectively. For the future prospective, the Ro-MMF can be integrate with the wavelength division scheme to further enhance the capacity of transmission system. 


\section{ACKNOWLEDGEMENT}

The author would like to thanks to Mr. Sanjay Gupta from GigaSoft India for providing valuable resources to complete this research.

\section{REFERENCES}

[1] Zin, A. M., et al. "An overview of radio-over-fiber network technology."Photonics (ICP), 2010 International Conference on. IEEE, 2010.

[2] Yu, Jianjun, et al. "A novel radio-over-fiber configuration using optical phase modulator to generate an optical mm-wave and centralized lightwave for uplink connection." Photonics Technology Letters, IEEE 19.3 (2007): 140-142.

[3] $\mathrm{Yu}$ et.al. "Bidirectional radio-over-fiber system with phase-modulation downlink and RF oscillator-free uplink using a reflective SOA." Photonics Technology Letters, IEEE 20.24 (2008): 2180-2182.

[4] Larrodé, M. García, and A. M. J. Koonen. "All-fiber fullduplex multimode wavelength-division-multiplexing network for radio-over-multimode-fiber distribution of broadband wireless services." Microwave Theory and Techniques, IEEE Transactions on 56.1 (2008): 248-255.

[5] Nirmalathas, Ampalavanapillai, et al. "Wavelength reuse in the WDM optical interface of a millimeter-wave fiberwireless antenna base station." Microwave Theory and Techniques, IEEE Transactions on 49.10 (2001): 20062012.

[6] Ferreira, Filipe M., Daniel Fonseca, and Henrique JA da Silva. "Design of Few-Mode Fibers With M-modes and Low Differential Mode Delay." Journal of Lightwave Technology 32.3 (2013): 353-360.

[7] Yuen, Roland, Xavier N. Fernando, and Sridhar Krishnan. "Radio over multimode fiber for wireless access." Electrical and Computer Engineering, 2004. Canadian Conference on. Vol. 3. IEEE, 2004.

[8] Cseh, Tamas, and TiborBerceli. "Improved receiver techniques for Radio over Multimode fiber systems." Network and Optical Communications (NOC), 2013 18th European Conference on and Optical Cabling and Infrastructure (OC\&i), 2013 8th Conference on. IEEE, 2013.

[9] Lethien, C., C. Loyez, and J-P. Vilcot. "Potentials of radio over multimode fiber systems for the in-buildings coverage of mobile and wireless LAN applications."Photonics Technology Letters, IEEE 17.12 (2005): 2793-2795.

[10] Tan, C. M., et al. "Transmission of ultra wide band radio using multimode radio-over-fiber system." Microwave
Conference Proceedings, 2005. APMC 2005. AsiaPacific Conference Proceedings. Vol. 2. IEEE, 2005.

[11] M.L. Yee, C.K. Sim, B. Luo, L.C. Ong, M.Y.W.Chia, "Performance Evaluation for WLAN, Ethernet and UWB co-existence on Hybrid Radio-Over-Fiber Picocells", Optical Fiber Communications Conference 2005, Anaheim, USA. Mar 2005.

[12] Safaisini, Rashid, et al. "20 Gbit/s data transmission over $2 \mathrm{~km}$ multimode fibre using $850 \mathrm{~nm}$ mode filter VCSEL." Electronics Letters 50.1 (2014): 40-42.

[13] Kim, Ji Won, et al. "High-power radially-polarized Er: YAG laser with Laguerre-Gaussian (LG01) mode output." CLEO: Science and Innovations. Optical Society of America, 2011.

Pardeep kaur received the Diploma in Electronics and communication Engineering From Thapar Polytechnic College, Patiala in 2009 and B.Tech degree from University college of Engineering, Punjabi university, Patiala in 2012. She is pursuing M.Tech in ECE from Department of Electronics and communication Engineering, University college of Engineering, Punjabi university, Patiala. Her research interests include Hybrid Radio over Fiber transmission system, High-speed optical communication technologies.

Rajbir kaur received B.Tech degree in Electronics and Communication Engineering from Nagpur University, Maharashtra and M.Tech degree in ECE from Punjab technical university, Jalandhar. She is pursuing

Ph.D in Wireless communication from Department of Electronics and communication Engineering, University college of Engineering, Punjabi university, Patiala and currently working as Assistant Professor in university college of Engineering, Punjabi University, Patiala. Her area of interest is analog and digital communication systems.

Sushank Chaudhary has done M.Tech in Optical communication from Govt Engineering College, Ferozepur (Punjab) in 2012, B.Tech in Electronics \& Communication from Govt. Engineering College, Lehragaga (Punjab) in 2010 and Diploma in Electronics and Communication Engineering from Govt.Polytechnic College, Rohroo (Himachal Pradesh) in 2007.

He joined GigaSoft India (Optiwave Corp.) as Sr. Research Associate in April 2012.His major responsibilities are to provide technical support and training regarding Optiwave Software's (OptiSystem, OptiFiber, OptiGrating, OptiFDTD, OptiBPM , OptiSpice ) to the various R \& D's as well as repudiated engineering institutions as research point of view. Presently he is doing $\mathrm{PhD}$ in optical communication from InterNetworks Research Lab, Malaysia. 